\title{
Os conceitos de percepção e território como lentes para o entendimento cultural
}

\author{
Conceptos de percepción y territorio como lentes para el \\ entendimiento cultural
}

\section{Concepts of perception and territory as lenses for cultural understanding}

\author{
Luciene Cristina Risso \\ luciene@ourinhos.unesp.br \\ Professora Doutora da UNESP - Campus de Ourinhos
}

Resumo: O objetivo deste estudo foi realizar uma discussão teórico-metodológica a respeito dos conceitos de percepção e território para a leitura cultural. Isto porque o território, entendido subjetivamente, possibilita a leitura dos significados inerentes às paisagens. Nesse caso, a percepção das sociedades, com relação aos espaços vividos e aos lugares, traz a complementaridade e a integração entre os dois conceitos. Dessa forma, a Geografia Cultural torna-se essencial na discussão de comunidades tradicionais e indígenas em sua relação territorial.

Palavras-chave: Território. Comunidades indígenas e tradicionais. Percepção.

Resumen: El objetivo de este estudio fue realizar un debate teórico y metodológico de los conceptos de percepción y el territorio para la lectura cultural. Esto es porque el territorio, entendido subjetivamente, permite la lectura de los significados inherentes en los paisajes. En este caso, la percepción de las personas con respecto a sus experiencias en los espacios y lugares trae la complementariedad y la integración entre los dos conceptos. Por lo tanto, la geografía cultural es fundamental en la discusión de las comunidades tradicionales e indígenas en su relación territorial.

Palabras-Clave: Territorio. Comunidades indígenas y tradicionales. Percepción.

Abstract: The aim of this study was to develop a theoretical and methodological discussion about the concepts of perception and territory for a cultural reading. The subjective understanding of territory enables the reading of meanings inherent to the landscapes. In this study, the perception of societies in relation to lived spaces and places complements and integrates the two concepts. Thus, Cultural Geography becomes essential in the discussion of traditional and indigenous communities in their territorial relation.

Keywords: Territory. Indigenous and traditional communities. Perception. 


\section{INTRODUÇÃO}

Este artigo enquadra-se nos estudos da Geografia Humanística, a qual tem como proposta entender e valorizar o subjetivo, ou seja, as experiências, os valores, os sentimentos com relação às paisagens, aos espaços e aos lugares.

O marco desta corrente teórica vincula-se à publicação de Tuan, em 1976, do artigo Humanist Geography. No Brasil, após a tradução em 1980 do livro Topofilia, de Tuan, essas teorias se propagaram e, hoje, estão estritamente relacionadas com a Geografia Cultural.

No Brasil, ao longo de 34 anos, os conceitos da Geografia Cultural se consolidaram, ampliando-se o debate acerca dos conceitos de espaço vivido, lugar, paisagem e percepção. No entanto, observa-se uma lacuna relativa ao conceito de território, que foi pouco explorado no contexto desta corrente; assim, este artigo ressalta as contribuições de Bonneimason (2002), o intelectual mais importante no que concerne a essa abordagem. Suas contribuições foram e são ímpares para quem estuda territórios diferenciados. Portanto, o objetivo principal desse artigo é apresentar o conceito de território do ponto de vista cultural, incluindo a percepção como apoio a tais compreensões.

Realizou-se uma breve revisão dos pensares relativos ao território, bem como das contribuições teóricas mais atualizadas, no contexto brasileiro. Destaca-se, principalmente, Haesbaert (2006), que vê o território de forma mais ampla, considerando a imaterialidade presente, e não somente a materialidade.

Parece-nos pertinente debatermos esses temas e, sobretudo, valorizarmos e propagarmos as ideias da Geografia Cultural Humanística, que, num mundo tão "frio", vem acalentar as pesquisas, valorizando, ouvindo as pessoas e considerando as pessoas. Embora muitos ainda pensem que essa corrente teórica está permeada por romantismos, isso constitui uma inverdade. Trata-se, de fato, de dar espaço às pessoas, visando compreender suas experiências geográficas.

\section{PERCEPÇÃO}

Compreender a relação de uma sociedade com seu território, através da lente da Geografia Cultural Humanística, significa interpretar as experiências adquiridas pelas sociedades que são formadas por "uma longa sucessão de percepções." (TUAN, 1980, p.4).

O quê, então, é percepção? O conceito é bem complexo, mas essencial para os estudos culturais e sociais. Nos Estados Unidos, os estudos de percepção na Geografia surgiram dentro da escola Geográfica denominada Humanista ou Humanística, durante os anos de 1970. Tais estudos contrapunham-se à Geografia Tradicional. (HOLZER, 1992). Seu precursor foi Y-Fu-Tuan, uma referência contemporânea fundamental.

As pessoas percebem o mundo ao redor através dos órgãos dos sentidos e da cognição, que, embora sejam individuais e seletivos (pois passam por filtros culturais e sociais), compartilham de percepções comuns, como assegura Tuan (1980). 
Para Tuan (1980) a percepção "é tanto a resposta dos sentidos aos estímulos externos como a atividade proposital, nas quais certos fenômenos são claramente registrados, enquanto outros retrocedem para a sombra ou são bloqueados". O processo envolve os aspectos biológicos como aspectos culturais:

[...] muito do que percebemos tem valor para nós, para a sobrevivência biológica, e para propiciar algumas satisfações que estão enraizadas na cultura. Atitude é primariamente uma postura cultural, uma posição que se toma frente ao mundo. Ela tem maior estabilidade do que a percepção e é formada de uma longa sucessão de percepções, isto é, de experiências. (TUAN, 1980, p.4).

A percepção tem por base a cognição. Segundo Del Rio (1996, p.3) a percepção é um "processo mental de interação do indivíduo com o meio ambiente que se dá através de mecanismos perceptivos propriamente ditos e, principalmente cognitivos". Este processo resulta em diferentes representações, significados, percepções, ações e condutas.

Os filtros culturais são essenciais nesse processo, já que selecionam as informações recebidas, conferindo-lhes significados diferenciados. Como resultado, Tuan (1980, p.14) diz que "(...) não somente as atitudes para com o meio ambiente diferem, mas difere a capacidade real dos sentidos."

Mesmo em ambientes com condições geográficas similares, o modo como uma determinada sociedade se relaciona com a Natureza e se apropria dela é diferenciado. Portanto, não se trata de determinismo geográfico, mas são formas criativas do processo de percepção ambiental (influenciado pela cultura) que atuam na criação e transformação das paisagens.

Já para Merleau-Ponty (1999, p.287) a percepção é a "consciência de..." ela revela os objetos assim como uma luz os ilumina na noite." (Merleau-Ponty, 1999, p.324). Para esse autor os 'sentidos' são (só) "instrumentos da excitação corporal e não da própria percepção". E reforça "os sentidos não existem, mas apenas a consciência." (MERLEAU-PONTY, 1999, p.293), "[...] se eu quisesse traduzir exatamente a experiência perceptiva, deveria dizer que se percebe em mim e não que eu percebo." (MERLEAU-PONTY, 1999, p.290).

Desse modo, a percepção sendo consciência de, vai criando e (re)criando experiências na dimensão existencial, fazendo com que tenham espacialidades. Essas experiências estão presentes em territórios e em paisagens, de forma material e imaterial. Assim, o território é constituído de espaços e lugares que possuem valores e simbolismos amalgamados, que podem ser estudados e revelados.

Porém, esses estudos, dentro da fenomenologia, consideram o ser humano não como objeto da pesquisa, mas sujeito da pesquisa, pois "sem perceber que ele mesmo percebe que é sujeito perceptivo e que a percepção, tal como ele a vive, desmente tudo o que ele diz da percepção em geral." (MERLEAU-PONTY, 1999, p.279). E ainda: “[...] o mundo não é perfeitamente explícito diante de nós, por que ele só se desdobra pouco a pouco e nunca 'inteiramente', enfim como ocorre que nós o percebamos? Nós só o compreenderemos se o eu empírico e o corpo não forem imediatamente objetos [...]." (MERLEAU-PONTY, 1999, p.281). 
Estamos sempre num contínuo processo perceptivo e nossas experiências estão presentes espacialmente. “Experienciar”, segundo Tuan (1983, p.10) "é aprender; significa atuar sobre o dado e criar a partir dele".

A experiência é um termo chave para Tuan (1983, p.18), no livro "Espaço e Lugar". Para ele a experiência envolve uma teia de sensações, percepções e concepções, emoções e pensamentos. E, portanto, "os espaços do Homem refletem a qualidade dos seus sentidos e sua mentalidade".

Todavia, como são e/ou como se dão essas experiências humanas com os espaços e lugares? Para Tuan (1983) o espaço é a condição para a sobrevivência, mas não somente, pois o espaço "como recurso é uma apreciação cultural", que tem atributos psicológicos e até espirituais.

Nesse prisma, Tuan (1983, p.6) diferencia espaço e lugar da seguinte forma: “Espaço é mais abstrato do que lugar. O que começa como espaço indiferenciado transformase em lugar à medida que o conhecemos melhor e o dotamos de valor". "Vivemos no espaço... as grandes planícies dão a sensação de "espaciosidade". O lugar é segurança e o espaço é liberdade: estamos ligados ao primeiro e desejamos o outro." (TUAN, 1983, p.3). E complementa, "[...] os seres humanos necessitam de espaço e lugar. As vidas humanas são um movimento dialético entre refúgio e aventura, dependência e liberdade." (TUAN, 1983, p.61).

O território, portanto, possui lugares com centralidade valorativa. As sociedades inspiraram significados e sentimentos em relação aos lugares. Os lugares remetem aos sonhos, conforto, devoção. Tuan (1980, p.130) diz que "em qualquer lugar onde haja seres humanos, haverá o lar de alguém - com todo o significado afetivo da palavra". Nessa direção, esses lugares interiorizam-se nos territórios, tornando-os territórios culturais. No entanto, os resultados desse processo podem significar topofilia (expressão de Bachelard) ou topofobia. Por topofilia, entende-se "o elo afetivo entre a pessoa e o lugar ou ambiente físico" (TUAN, 1980, p.5); topofobia, por sua vez, refere-se à repulsa com relação ao lugar.

Concernente a esses sentimentos "experienciados", Machado (1996) demonstra que, para os moradores da serra do mar, esta área não é apenas um espaço, mas um lugar imerso em valores e sentimentos vinculados à paisagem. Já para os estudiosos e planejadores, a mesma área é vista apenas como espaço ou paisagem, sob a ênfase conceitual.

É importante destacar essas duas visões, porque mostra de certa forma, a sensibilidade que se deve ter quando se trata do respeito às terras indígenas e outras terras tradicionais, pois seus territórios são lugares, no sentido mais profundo da palavra, com "mundivivências" totalmente únicas em todo o Universo.

Encontrar, por fim, as experiências que se sobressaem nesses espaços ou lugares presentes em um determinado território, torna-se fundamental para as pesquisas. E a Geografia Cultural e Humanística deve continuar avançando nesse ousado caminho da leitura do subjetivo. O caminho não é fácil. Como Tuan (1983) mesmo coloca, as experiências estão sendo deixadas de lado:

[...] Uma grande quantidade de dados provenientes da experiência está destinada ao esquecimento porque não podemos encaixar as informações nos conceitos das 
Ciências Físicas que 'aceitamos sem criticar'. Curiosamente, esta cegueira para com a profundidade da experiência aflige tanto o Homem da rua como o cientista social. (TUAN, 1983, p.222).

O reconhecimento da importância dos estudos da percepção e das experiências implica, enfim, valorizarmos cada vez mais essa corrente teórico-geográfica, que percebe e é percebida, que sente e é sentida.

\section{O CONCEITO DE TERRITÓRIO NA ÓTICA CULTURAL}

O entendimento do território na ótica cultural demanda uma direção de apropriação, não somente material e política do espaço, mas imaterial e simbólica.

Antes de abordarmos a dimensão imaterial, lembremos que o conceito de território não se originou no âmbito da Geografia, pois foi trazido pelos geógrafos da Biologia. Segundo Haesbaert (2006, p.36) a primeira obra referente ao tema, na Geografia, foi de Malmberg (1980), fundamentada no behaviorismo e, por isso, muito criticada.

Essas concepções extrapolaram o debate da territorialidade animal (que, por sinal, também é complexa e difícil de generalizar), chegando ao mundo da territorialidade humana (vide estudos de Ardrey,1969), no sentido, principalmente, de defesa e agressão que, claro, não corresponde ao mundo social.

Haesbaert (2006, p.51) adverte que são teses ainda não "sepultadas", "pelo contrário, a tendência é de que ganhem novo fôlego, especialmente a partir dos avanços no campo biogenético".

Na Geografia, referências significativas acerca do conceito de território vieram de Gottman (1975) e Raffestin (1993), que se direcionaram para uma vertente mais política.

Gottman (1975) realizou uma revisão sobre a evolução conceitual do território, afirmando que, de um pensamento geopolítico o conceito evoluiu, gradativamente, para um pensamento econômico e social. Para ele "território é uma porção do espaço geográfico que coincide com a extensão espacial da jurisdição de um governo." (GOTTMAN, 2012, p.1). Essas ações têm concretude material e político-ideológica, e "[...] muda o significado do território conforme se reorganiza a sociedade." (SAQUET, 2007, p.59).

Raffestin (1993) é um autor que se tornou clássico. Embora com um foco político, a novidade trazida por ele relaciona-se à inserção da dimensão social. Raffestin entende que o território é fruto da apropriação social por sociedades, e não somente pelo poder estatal. É "um espaço onde se projetou o trabalho [...] é a prisão que os homens constroem para si" e ainda, "o território se apoia no espaço, mas não é o espaço; é uma produção, a partir do espaço." (RAFFESTIN, 1993, p.144). Depreende-se, então, que o espaço para o autor é a base desse processo.

O autor ainda fala da questão dos limites:

[...] Falar de território é fazer uma referência implícita à noção de limite que, mesmo não sendo traçado, como em geral ocorre, exprime a relação que um grupo mantém 
com uma porção do espaço. A ação desse grupo gera, de imediato, a delimitação. (RAFFESTIN, 1993, p.153).

Na questão da territorialidade, Raffestin (1993, p.158) comenta que esta "reflete a multidimensionalidade do vivido territorial pelos membros de uma coletividade, pelas sociedades em geral", e que ela não é somente uma relação com o território, mas, pode ser definida "como um conjunto de relações que se originam num sistema tridimensional sociedade, espaço e tempo." (RAFFESTIN, 1993, p.160). O autor ainda dá outras definições de territorialidade:

[...] se inscreve no quadro da produção, da troca e do consumo das coisas. Conceber a territorialidade como uma simples ligação com o espaço seria fazer renascer um determinismo sem interesse. É sempre uma relação, mesmo que diferenciada, com os outros atores. (RAFFESTIN, 1993, p.161).

[...] resume, de algum modo, a maneira pela qual as sociedades satisfazem, num determinado momento, para um local, uma carga demográfica e um conjunto de instrumentos também determinados, suas necessidades em energia e em informação. (RAFFESTIN, 1993, p.161).

No entanto, o autor tratado considera mais a questão da apropriação da materialidade, o que, no caso dos estudos e pesquisas com sociedades tradicionais e indígenas, não é suficiente. Para Haesbaert (2010, p.170), muitos outros como Sack (1986) e Souza (1995) focaram mais na questão política. Atualmente, Haesbaert (2006, 2010), Saquet (2007) dentre outros, estão contribuindo para a discussão epistemológica.

Para Haesbert (2006) território "pode ser concebido a partir da imbricação de múltiplas relações de poder, do poder mais material das relações econômico-políticas ao poder mais simbólico das relações de ordem mais estritamente cultural." (HAESBAERT, 2006, p.79). Em sua análise, não se pode conceber territórios puramente simbólicos e nem puramente funcionais.

O interessante desse conceito é que o mesmo abarca não só a materialidade, mas também a dimensão simbólica. Sua visão de território é integradora. Discute, ainda, sobre desterritorialização, a qual considera um mito, pois não há o "fim dos territórios", "dos que imaginam que o Homem pode viver sem território, que a sociedade pode existir sem territorialidade" (HAESBAERT, 2006, p.16), mas, sim a formação de multiterritórios, ou seja, uma forma de reterritorialização, que vai depender "sobretudo do contexto social, econômico, político e cultural em que estamos situados.” (HAESBAERT, 2006, p.354).

Moraes (2005, p.149) também é contrário aos pensamentos de enfraquecimento do Estado e fim dos territórios, ao dizer, que vários acontecimentos atuais estão reiterando "os fracionamentos geopolíticos e a diferenciação dos lugares"; e reforça que:

[...] as culturas nacionais não mostram a diluição numa identidade global, apregoada por muitos há poucos anos passados, ao contrário, assiste-se a certo revigoramento na luta pela autodeterminação e da manutenção de vantagens de sociedades espacialmente circunscritas. (MORAES, 2005, p.149). 
Saquet (2007), desde o início dos anos 2000, vêm estabelecendo argumentações para articular tempo, espaço e território, centrado no conceito de produção social do espaço. Atualmente, está empenhado em incluir a imaterialidade na sua discussão. Assim, o território, para esse autor, é:

[...] apropriado e construído socialmente, resultado e condição do processo de territorialização; é produto do processo de apropriação e domínio social, cotidianamente, inscrevendo-se num campo de poder, de relações socioespaciais, nas quais, a natureza exterior ao homem está presente de diferentes maneiras como mencionamos em Saquet (2003/2001 e 2004). (SAQUET, 2007, p.58).

Desse modo, essas reavaliações demonstram que a Geografia atual está valorizando o conceito de território, contribuindo para a análise do espaço geográfico.

No caso deste estudo, quando se analisa o território das comunidades indígenas e tradicionais percebe-se que estas concebem e vivem nesses lugares de formas diferenciadas. Assim, não se entende o território somente como poder material, mas, principalmente, se deve entender o território simbólico, como lugar afetivo.

Privilegia-se, então, um enfoque mais específico, numa abordagem cultural, mesmo considerando a indissociabilidade entre materialidade e a imaterialidade do território como conceituou Haesbaert (2006). Suas concepções são muito interessantes para a Geografia Cultural. Ressaltamos que, aqui, não há ambiguidade, pelo contrário, é uma abordagem que pode associar-se à Geografia Humanística.

No entanto, é inegável a dificuldade em integrar essas dimensões (material e imaterial) diante da complexidade teórico-metodológica de ambas. Há um grande arcabouço teórico advindo da Geografia Humanística e da Geografia Cultural que, historicamente, teorizam sobre a abordagem cultural. Tal arcabouço não pode ser negligenciado, implicando que esses estudos subjetivos têm sua própria história, não se configurando, portanto, um debate novo.

O conceito de território de Bonneimason (2002, p.101) é bem apropriado para os estudos culturais em territórios culturais tradicionais, quando afirma que o território é "um tipo de relação afetiva e cultural com uma terra, antes de ser um reflexo de apropriação ou de exclusão do estrangeiro".

Para ele, o território "é, ao mesmo tempo, 'espaço social' e espaço 'cultural': ele está associado tanto à função social quanto à função simbólica." (BONNEIMASON, 2002, p.103), ao qual cultura está associada ao território:

[...] a ideia de cultura, traduzida em termos de espaço, não pode ser separada da ideia de território. É pela existência de uma cultura que se cria um território e é por ele que se fortalece e se exprime a relação simbólica existente entre a cultura e o espaço. (BONNEIMASON, 2002, p.102).

"A cultura penetra no espaço" (BONNEIMASON, 2002, p.105) e, assim, o território se constrói, ao mesmo tempo, como um sistema e um símbolo. (BONNEIMASON, 2002, p.106). Um sistema porque se organiza e se hierarquiza para responder às necessidades 
e funções assumidas pelo grupo que o constitui. Um símbolo porque se forma em torno de polos geográficos que comandam sua visão de mundo, criando, assim, representações geossimbólicas.

Quanto ao conceito de territorialidade, Bonneimason (2002, p.107) diz que "a territorialidade é a expressão de um comportamento vivido: ela engloba, ao mesmo tempo, a relação com o território e, a partir dela, a relação com o espaço estrangeiro". E ainda, que:

[...], por conseguinte, a territorialidade é compreendida muito mais pela relação social e cultural que um grupo mantém com a trama de lugares e itinerários que constituem seu território do que pela referência aos conceitos habituais de apropriação biológica e de fronteira. Assim, existem povos para quem a noção de fronteira é praticamente inexistente, sem que isso signifique que eles não tenham território. (BONNEIMASON, 2002, p.99/100).

É, também, no território que se constrói a identidade individual e a social e cultural, para o autor:

[...] os geógrafos devem procurar compreender a concepção de mundo que existe no coração do grupo ou da sociedade que estejam estudando. Isso menos pelo estudo da representação cultural em si mesma, mas, sobretudo pelo estudo de suas expressões espaciais. Trata-se aí de reencontrar os lugares onde se exprime a cultura e, depois, a espécie de relação secreta e emocional que liga os homens à sua terra e, no mesmo movimento, funda sua identidade cultural. (BONNEIMASON, 2002, p.103).

O conceito de identidade cultural se caracteriza por sua polissemia e fluidez, remetendo, primeiramente, à questão abrangente da identidade social. Para a psicologia social, a identidade é um instrumento que permite pensar a articulação do psicológico e do social em um indivíduo. "A identidade permite que o indivíduo se localize em um sistema social e seja localizado socialmente." (CUCHE, 1999, p.177).

A identidade social extrapola o indivíduo, pois, o grupo também é dotado de uma identidade, definindo seu papel e sua inserção no conjunto social. Dessa forma, o conceito de identidade trabalha com alteridade. Ao mesmo tempo em que ela identifica, ela diferencia. "Identidade e alteridade estão ligadas e estão em uma relação dialética. A identificação acompanha a diferenciação" (CUCHE, 1999, p.183). A diferença não somente identifica os grupos, mas também os lugares. (RATTS, 2003, p.37).

A identidade cultural é o sentimento de ser e pertencer a um lugar e a um grupo específico. Para Barth (1969), a identidade se constrói e reconstrói, constantemente, no interior das trocas sociais. No processo de identificação, o principal é marcar as fronteiras (sociais, simbólicas) entre nós e os outros. O autor salienta, ainda, que a fronteira se estabelece pela vontade de se diferenciar e pelo uso de certos traços culturais como marcadores de sua identidade específica.

Sobre a delimitação de fronteiras étnicas, diz Claval (2001):

[...] os sentimentos de identidade tem consequências geográficas aparentemente contraditórias: eles favorecem, através do sentimento de territorialidade, a emergência 
de espaços culturalmente homogêneos, e, ao mesmo tempo, permitem aos indivíduos ou aos grupos manterem suas especificidades quando estão misturados entre si. $\mathrm{O}$ cuidado em preservar sua identidade não impede o estabelecimento de relações com aqueles que são diferentes, mas introduz limites que proíbem a aceitação daquilo que ameaça os valores centrais que foram adotados. (CLAVAL, 2001, p.181).

Contudo, nem sempre um grupo se autodenomina de uma determinada etnia ou de outros tipos sociais, por uma série de motivos. Por exemplo, até pouco tempo atrás, assumir-se como índio era vergonhoso, devido ao estigma negativo imposto por nossa sociedade, portanto, havia uma tendência de ocultação dessa identidade. (CUNHA, 1987, p.117).

Após 1988, com a Constituição Federal que reconheceu o direito imemorial à terra, os grupos, em sua maioria, não sentem vergonha de ser índio, pelo contrário, estão assumindo sua identidade e reivindicando a terra. Segundo Ratts (2003, p.39):

[...] Mostrar-se como índio é uma tática nova, é demarcar uma identidade que os distingue parcialmente do camponês genérico. Esse movimento diferencialista (parafraseando Lefebvre) é a marca do "aparecimento político" desses grupos. (RATTS, 2003, p.39).

Assim, a identidade se constrói através das estratégias dos atores sociais, ela é dinâmica, "um processo no tempo e no espaço." (RETAILLE, 1995, p.26).

Dessa forma, a identidade é multidimensional, considerando, assim, que nenhum indivíduo ou grupo está fechado em uma identidade unidimensional, antes, pertence também a outros grupos sociais. Por exemplo, no caso dos índios, existe um preconceito de que eles não podem se inserir em nossa sociedade; que, índio que é índio deve continuar confinado, sem consumir nossos produtos, e, em alguns casos, até sem direito ao acesso à saúde e educação. Tal cenário está mudando, por causa da luta deles próprios, mas, nossa sociedade se esmera na manutenção dos mais variados preconceitos. Portanto, discutir território e identidade significa, igualmente, abrir os horizontes para um pensamento aberto, humanístico e ético.

\section{CONSIDERAÇÕES FINAIS}

Longe de ser uma conclusão, pretendemos, aqui, reafirmar a riqueza do debate sobre as concepções tratadas neste artigo, enfatizando que o diálogo é permanente.

O importante é ter clareza na escolha de suas concepções geográficas, tendo o cuidado de usar autores de modo dialógico. Para isso, estudar produções atuais, bem como revisitar as leituras clássicas, pontuando as ideias principais dos autores, é essencial para não se ter trabalhos nos quais é perceptível um misto de ideias, muitas vezes contraditórias, de conceitos relativos à paisagem e ao território.

Enfim, esperamos contribuir com os estudos territoriais, aos quais os conceitos de percepção e território são fundamentais para a leitura cultural, principalmente para 
estudos cujos sujeitos da pesquisa são as comunidades tradicionais e indígenas, pois abrangem as multiplicidades sociais e as cosmovisões presentes.

Essa forma de analisar reflete um pensamento na diversidade e na sensibilidade para as questões territoriais, já que os territórios das comunidades indígenas e tradicionais são dotados de outros sentidos e significados, frutos de interesses construídos coletivamente.

O território, portanto, tem historicidade, tem várias dimensões, mas, sobretudo, tem memórias, identidades e simbolismos. E, assim, nesse caminho da Geografia Humanística, não se nega a materialidade, mas se escolhe compreender, também, a subjetividade presente no espaço.

\section{REFERÊNCIAS}

ALMEIDA, M.G.; VARGAS, M.A.M.; MENDES, G.F. Territórios, paisagens e representações: um diálogo em construção. Mercator, v.10, n.22, p.23-35, 2011.

BARTH, F. Les groupes ethniques et leurs frontières. In: POUTIGNAT, P.; STREIFF-FERNART, J. Theories de l'ethnicité. Paris: Presses Universitaires de France, 1995. p.203-249.

BONNEIMAISON, J. Viagem em torno do território. In: CORREA, R.L.; ROSENDAHL, Z. Geografia cultural: um século. Rio de Janeiro: Ed. UERJ, 2002. p.83-132.

CLAVAL, P. A Geografia Cultural. Florianópolis: EDUSC, 1999.

CORREA, R.L. Espaço, um conceito-chave da Geografia. In: CASTRO, I.E; GOMES, P.C.C.; CORREA, R.L. Geografia: conceitos e temas. Rio de Janeiro: Bertrand Brasil, 1995. p. 15-47.

CUCHE, D. A noção de cultura nas ciências sociais. Bauru: EDUSC, 1999.

CUNHA, M.C. Antropologia do Brasil: mito, história e etnicidade. São Paulo: Brasiliense, 1987.

DEL RIO, V. Cidade da mente, cidade real, percepção e revitalização da área portuária do Rio de Janeiro. In: __ _ OLIVEIRA, L.(Orgs). Percepção ambiental: a experiência brasileira. São Paulo: Studio Nobel/ Ed. UFSCAR, 1996. p.3-22.

DEL RIO, V.; OLIVEIRA, L. (Orgs). Percepção ambiental: a experiência brasileira. São Paulo: Studio Nobel/ Ed. UFSCAR, 1996.

DELEUZE, G.; GUATTARI, F. Mil platôs. São Paulo: Editora 34, 1997. v.5.

DUNCAN, J. A paisagem como sistema de criação de signos. In: CORREA, R.L.C.; ROSENDAHL, Z. Paisagens, textos e identidade. Rio de Janeiro: Ed. UERJ, 2004. p. 91-132.

GOTTMANN, J. A evolução do conceito de território. Boletim campineiro de Geografia, v. 2, n.3, 2012. (fac-símile do original de 1975).

HAESBAERT, R. O mito da desterritorialização: do fim dos territórios à multiterritorialidade. 2. ed. Rio de Janeiro: Bertrand Brasil, 2006.

HAESBAERT, R. Regional-global: dilemas da região e da regionalização na geografia contemporânea. Rio de Janeiro: Bertrand Brasil, 2011.

HAESBAERT, R. Territórios alternativos. 2.ed. São Paulo: Contexto, 2006.

HOLZER, W. A Geografia humanista: sua trajetória de 1950 a 1990. 1992. Dissertação (Mestrado em Geografia) - Universidade Federal do Rio de Janeiro, Rio de Janeiro, RJ. 
MACHADO, L. M.C.P. Paisagem valorizada: a Serra do Mar como espaço e como lugar. In: DEL RIO, V.; OLIVEIRA, L. (Orgs). Percepção ambiental: a experiência brasileira. São Paulo: Studio Nobel/ Ed. UFSCAR, 1996. p. 97-120.

MERLEAU-PONTY, M. Fenomenologia da percepção. 2.ed. São Paulo: Martins Fontes, 1999.

MORAES, A.C.R. Território e História no Brasil. 2.ed. São Paulo: Annablume, 2005.

RAFFESTIN, C. Por uma geografia do poder. São Paulo: Ática, 1993.

RATTS, A.J.T. A geografia entre as aldeias e os quilombos: territórios etnicamente diferenciados. In: ALMEIDA, M.G.; RATTS, A.J.P. (Orgs.). Geografia: leituras Culturais. Goiânia: Alternativa, 2003. p. $29-48$.

RETAILLE, D. Etnogeographie: naturalisation des formes socio-spaciales. In: CLAVAL, P.; SINGARAVELOU, (Orgs.). Ethnogéographies. Paris: L'Harmattan, 1995. p. 17-38.

SACK, R. Human territoriality: its theory and history. Cambridge: University Press, 1986.

SAQUET, M. A. As diferentes abordagens do território e a apreensão do movimento e da (i)materialidade. Geosul, Florianópolis, v. 22, n. 43, p 55-76, jan./jun. 2007.

SERPA, A. Espaços culturais: vivências, imaginações e representações. Salvador: Ed. UFBA, 2008.

SOUZA, M. O território: sobre espaço e poder, autonomia e desenvolvimento. In: CASTRO, I. et al. (Org.). Geografia: conceitos e temas. Rio de Janeiro: Bertrand Brasil, 1995.

TUAN, Yi-Fu. Espaço e lugar: a perspectiva da experiência. São Paulo: Difel, 1983.

TUAN, Yi-Fu. Topofilia: um estudo da percepção, atitudes e valores do meio ambiente. São Paulo: Difel, 1980. 